\title{
La crisis de la Unión Europea, ¿una oportunidad para la constitucionalización de la Unión? El papel de los Estados miembros
}

\author{
Irene Correas Sosa \\ Profesor Colaborador Doctor \\ Departamento de Derecho Constitucional. Universidad San Pablo CEU
}

Recibido: 01.10 .2012

Aceptado: 15.10.2012

Resumen: La Unión Europea se encuentra hoy en un momento de crisis que nos ofrece una extraordinaria oportunidad para replantear, redefinir y sentar las bases que definan los siguientes pasos de la construcción europea, que hoy parecen conducir a la definitiva constitucionalización, o metaconstitucionalización, como ha sido definida por algunos autores, de la Unión, enfrentándose a retos como la consecución de una ciudadanía europea, o la definición del papel de los Estados Miembros en una futura y definitiva unión política.

Palabras clave: Crisis, Unión Europea, Constitucionalización, ciudadanía, Estados Miembros.

Abstract: The European Union faces a crisis which offers a great opportunity to rethink, redefine and set the new basis for further steps of the European development. This seems to lead to a definitive constitutionalization, or metaconstitutionalization, as some authors had already defined it. It is facing challenges such as the achievement of an European citizenship, or the definition of the Member States role in a future political union.

Key words: Crisis, European Union, Constitutionalization, citizenship, Member States.

Sumario: 1. Introducción.-2. La crisis europea. ¿Crecimiento o estancamiento? - 3. El papel de los Estados en el proceso constitucional y el logro de la unión política.- - 4. ¿Realmente es imprescindible una Constitución europea?-5. Conclusiones.

\section{INTRODUCCIÓN}

Las crisis ofrecen habitualmente escenarios propicios para proceder a un replanteamiento de las estructuras, en ocasiones incluso a una redefinición de las mismas. De hecho, a lo largo de la historia ha sido frecuente que tras momentos de crisis se haya procedido a grandes, y en muchas ocasiones, no siempre, beneficiosos cambios. La Unión Europea no es ajena a esta circunstancia, de hecho podemos decir que su propio nacimiento vino de una crisis y de la necesidad no sólo de buscarle solución sino de evitar posteriores conflictos entre los países europeos, de construir un entorno de paz en un contexto de 
postguerra ${ }^{1}$. Así se expresaba Schumman en su conocida Declaración Schumman de 9 de mayo de 1950 «la paz mundial no puede salvaguardarse sin unos esfuerzos creadores equiparables a los peligros que la amenazan. La contribución que una Europa organizada y viva puede aportar a la civilización es indispensable para el mantenimiento de unas relaciones pacíficas. Francia, defensora desde hace más de veinte años de una Europa unida, ha tenido siempre como objetivo esencial servir a la paz. Europa no se construyó y hubo la guerra. Europa no se hará de una vez ni en una obra de conjunto: se hará gracias a realizaciones concretas, que creen en primer lugar una solidaridad de hecho. La agrupación de las naciones europeas exige que la oposición secular entre Francia y Alemania quede superada (...) $\rangle^{2}$.

En los sesenta años que han pasado desde su constitución podemos afirmar sin temor a equivocarnos que de hecho han sido las crisis las que han provocado avances en la Unión, cuando, tras momentos de estancamiento o incluso de aparente retroceso, se producía un nuevo avance.

Hablar actualmente de la crisis de la Unión Europea exige plantearse en primer lugar de cuál de las crisis hablamos. En nuestro grave contexto actual hablar de crisis puede llevarnos a pensar en crisis económica o financiera, que evidentemente afecta a la Unión Europea, como hemos visto muy especialmente desde el último verano. Pero debemos plantearnos que la crisis económica no es sino un elemento más del actual proceso de crisis, o de cambio, en que se encuentra la Unión.

Difícil sería acertar con exactitud qué ocurrirá tras estos años en que nos encontramos, pero no creo que nos equivoquemos si afirmamos con cierta rotundidad que asistimos a un profundo cambio que parece afectar no sólo ad intra sino incluso al papel de la Unión en el contexto internacional. En gran medida ese cambio tiene que ver con un reforzamiento del papel de la Unión como paraguas protector de los hoy debilitados Estados Miembros, de ahí que nos planteemos el proceso de constitucionalización de la Unión.

No tomamos como punto de partida el hecho de la existencia, o la necesidad de ella, de un texto positivo que, como las Constituciones de los Estados miembros contenga los principios y reglas básicas de conducta política y organización estatal de una realidad estatal o cuasiestatal. Por el contrario, partimos de de la consideración de que las evoluciones en la Unión han dado lugar a proceso cuasiconstitucional o metaconstitucional.

En este sentido, consideramos irrelevante que exista o no, al menos a priori, un texto constitucional europeo, por cuanto estimamos, como veremos en paginas siguientes, que el proceso no se puede realizar desde la creación de una constitución y desde allí amoldar los ordenamientos nacionales, sino

${ }^{1}$ Sobre los orígenes de la Unión podemos remitirnos, por todos, a SIDJANSKY D., El futuro federalista de Europa, Ariel, Barcelona, 1998, págs. 9 y ss.

${ }^{2}$ Puede consultarse el texto en http://europa.eu/abc/symbols/9-may/decl_es.htm 
justo al contrario, ha de surgir, como de hecho viene surgiendo, y aún cuando el proceso pueda resultar más lento, desde los ordenamientos nacionales.

Ello ocasiona, como de hecho hemos comprobado ya, que intentar dar forma a la unión política con una constitución, lejos de seguir su curso natural, y forzando, desde nuestro punto de vista, un proceso que se estaba produciendo de facto, terminó ocasionando su estancamiento.

Siendo ésta la situación en que nos encontramos, procede considerar si existen vías de solución. Para ello partiremos de lo que nosotros consideramos que son los actuales problemas que dificultan la unión política: la soberanía estatal, el papel de los Estados en la Unión, la existencia o no de una auténtica ciudadanía europea y el alejamiento de la Unión de los individuos, la necesidad de partir de principios comunes y convergentes que han de ser tenidos también en cuenta en futuros procesos de adhesión.

\section{LA CRISIS EUROPEA. ¿CRECIMIENTO O ESTANCAMIENTO?}

Los intentos de positivizar el proceso constitucional europeo han puesto de manifiesto no sólo el hecho de que es imposible imponer una realidad, en este caso la propia Unión Europea como comunidad de Estados, sin que ese realidad derive de los propios ciudadanos que la configuran y le dan forma y sentido. De esta manera coincidimos con BALAGUER CALLEJÓN cuando afirma que «esta conformación del Derecho constitucional europeo sobre las base de las tradiciones constitucionales comunes tanto por lo que se refiere a sus posibilidades de desarrollo cuanto por lo que se refiere a sus límites, pone en cuestión las pretensiones de una evolución diferente hacia nuevas formas de organización, desconocidas hasta ahora en el constitucionalismo y que se basan en la profundización en el carácter supranacional de las instituciones y los procedimientos de la Unión Europea» ${ }^{3}$.

Quizás no debamos trasponer las formas de construcción nacional a la Unión, pero no cabe duda de que existen determinados elementos que hacen en cierta forma inevitable buscar el paralelismo y, en la medida de lo posible, no imitar pero sí asimilar a una realidad que funciona ${ }^{4}$. No obstante, como

${ }^{3}$ BALAguer CALlejón, F., «Los tribunales constitucionales en el proceso de integración europea», Puede consultarse el texto en http://www.ugr.es/ redce/REDCE7/articulos/ 12 franciscobalaguercallejon.htm

${ }^{4}$ A pesar de que no sean extrapolables las categorías puras estatales sí es cierto que estamos ante una realidad paraestatal a la que le pudieran ser aplicables lo elementos tradicionales de un Estado, o debieran de serle aplicables ya que nos encontramos con una primera dificultad a la hora de definir el territorio de la Unión si tenemos en cuenta solicitudes de adhesión de territorios no europeos a Europa. Para poder trasladar en puridad, aún asumiendo que no estamos ante una realidad igual, consideramos que lo primero que debería definirse claramente es el territorio. En concreto me refiero a la adhesión de Turquía, que si bien no nos cabe duda de que no comparte principios comunes a los países europeos, su posible adhesión supone distintos intereses.

Puede consultarse al respecto, Beneyto, J. M. (Dir.), Arguerey, P., (Coord.) El impacto de la adhesión de Turquía en la Unión Europea, Instituto Universitario de Estudios 
decíamos, ello no puede suponer desconocer que es imprescindible tener en cuenta que lo que estamos intentando integrar son Estados soberanos con distintas realidades sociológicas, económicas e incluso políticas.

Precisamente porque nos encontramos ante distintas realidades es preciso tener al menos ciertos elementos en cuenta a la hora de valorar este proceso con fin ahora incierto, en el que nos encontramos.

No dudamos que la situación actual de la Unión Europea es de una crisis que podemos denominar global, lo que nos hace plantearnos que, asumiendo que efectivamente ha crecido y evolucionado tras sus sucesivas crisis, estamos ante un nuevo punto de inflexión hacia un nuevo desarrollo. Caso contrario, nos encontraríamos ante un nuevo estancamiento tras lo sucedido con el Tratado de Lisboa.

En este momento actual no podemos ignorar la importancia que juegan los Estados Miembros para reconducir la situación, de ahí que sea necesario interrogarse qué papel han de jugar y cómo pueden contribuir a ayudar a que la Unión afronte la crisis y salga de ella reforzada; de otra forma parece abocada, si no a desaparecer, sí a estancarse en su situación actual. Y, en cualquier caso, de una forma distinta de la que ha entrado en ella.

Con independencia de cuál sea nuestra postura sobre la Unión Europea, no podemos negar la importancia que reviste, lo que además hemos podido comprobar en estos momentos de debilidad estatal. No obstante, ello no debe cegarnos ante ciertos problemas de funcionamiento interno, que también se han puesto de manifiesto en la situación actual, en la que, ante la urgencia en la toma de decisiones éstas han sido tomadas por determinados Estados asumiendo como comunitarias lo que no eran sino decisiones movidas por intereses nacionales, aún cuando los comunitarios se vieran también beneficiados por ellas.

Esto nos conduce a uno de los problemas que hoy más se ponen de manifiesto, y es la crisis de legitimidad de la Unión que ha hecho tambalear lo que parecían unos cimientos sólidos, hasta que han tenido que enfrentarse a turbulencias y se han revelado como débilmente anclados, a pesar del consenso general que existe en su importancia ${ }^{5}$.

Europeos, Universidad CEU San Pablo, Biblioteca Nueva, Madrid, 2008, en particular Barroso Villaescusa, A., Torreblanca, J. I., «El impacto de una eventual adhesión turca sobre las instituciones comunitarias, la política exterior y el espacio de libertad, seguridad y justicia», pág. 41 y ss. Puede consultarse el texto en http://www.uned.es/dcpa/Profesores/126J IgnacioTorreblanca/126Publicaciones/Torreblanca_y_\%20Barroso_Turquia2008.pdf

${ }^{5}$ Sobre la crisis de legitimidad. Puede consultarse Schmitter, P. C., «¿Puede la gobernanza legitimar la Unión Europea?», European Journal of Legal Studies, puede consultarse el texto en http://www.ejls.eu/1/8ES.pdf, o Busch, K., HiRsCHEL, D., «Europa en la encrucijada. Propuestas para salir de la crisis», Tribuna global, puede consultarse en http://www.nuso.org/upload/articulos/3796_1.pdf

Sobre la legitimidad, o la doble legitimidad política de la Unión escribe CAMPINS ERITJA, M., en La constitución europea: entre lo intergubernamental y lo supranacional, Universidad de Barcelona, Barcelona, 2005, pág. 46 y ss. 
Es habitual que cuando nos planteamos el futuro de la Unión hablemos con frecuencia, como una dirección positiva hacia la que se ha de tender, de la aún lejana unión política, y como manifestación de ello, cómo lograr una Constitución para Europa. Pero realmente, parece como si no nos hubiéramos parado a preguntarnos si tenemos el sustrato sobre el que construirla y hacerla funcionar. La importancia que tiene saber contestar y poder además contrarrestar esta aparente crisis de legitimidad de la Unión nos preocupa, a efectos estudio, porque el caso contrario debilita los cimientos de la Unión, lo que dificulta aún más cualquier proceso constitucional, ya que, por sí mismo, es mucho más complicado en estados débiles desde el punto de vista económico, sociológico y sobre todo político, por carecer de una unidad y unas directrices claras. Pero además, periodos de convulsiones y crisis internas, incluso en el seno comunitario, no favorecen que se conduzca el proceso hacia la creación de un nucleo estable que le de unidad y coherencia interna, por carecer fundamentalmente de un acuerdo sobre quién y cómo ha de concluirse el proceso.

Precisamente por la necesidad de tener un corpus que de unidad a la futura unión política, cuando hablamos de este futuro se considera con frecuencia como una dirección positiva hacia la que se ha de tender la de la aún ansiada unión política, y como manifestación de ello, cómo lograr una Constitución para Europa. En este sentido, considera ALDECOA LUZÁRRAGA que «el riesgo de dilución de la integración que pudiera derivarse de las diferencias crecientes entre los Estados miembros de una Unión ampliada sólo puede combatirse con el pegamento de la Constitución Europea, cimiento del proyecto político compartido» ${ }^{6}$.

No vamos a negar nosotros el debate ni su importancia, de hecho es a dónde queremos llegar, pero quizás si sea conveniente que aún cuando podamos plantearnos la necesidad de articular el proceso sobre la base de un texto constitucional, consideramos que es quizás más relevante considerar qué hacerse que cómo ha de hacerse. Si no somos capaces de responder a la primera de las preguntas es imposible responder de forma definitiva a la segunda, por cuanto una depende de la otra, al ser la segunda, o al menos debiera ser así, un instrumento para articular la primera.

De esta forma si nos preocupamos mas del cómo que del qué, como parece haber hecho la Unión hasta ahora, debilitamos innecesariamente la Unión si fracasamos en un proyecto como el de dotar de una Constitución para Europa, cuando, por la vía de los hechos, puede lograrse lo mismo y, una vez asentada en la población proceder a la articulación jurídica, a dar forma a lo que en realidad es un hecho. De esta forma, el principal problema que le vemos al proceso, tal y como se ha ido desarrollando hasta ahora, es el hecho de que no existe una conciencia europea en la ciudadanía, es más, según

${ }^{6}$ Aldecoa luzárraga, F., «Construcción y constitución europea», Documentación Social, Madrid, núm. 134, 2004, pág. 20. 
hemos ido avanzando han ido apareciendo más voces euroescépticas o antieuropeas, lo que quizás alguno pueda interpretarse como un signo de la propia consecución de los objetivos, pero, considerando que el proceso estaba gestándose, desde nuestro punto de vista reflejan precisamente la falta de un objeto común ante el que se alzan, con anterioridad a su finalización, los que ven inconvenientes en la misma ${ }^{7}$.

Hemos de tener en cuenta que coincidimos con quiénes estiman que no hemos de proceder a la unión política asimilando la Unión a lo que fue la construcción de los estados nacionales, como ya hemos avanzado, dónde, sobre una base al menos mayoritariamente homogénea, se construían realidades estatales que se articulaban en base a la redacción de un texto constitucional; sino que estamos ante una proceso de construcción propio y distinto ${ }^{8}$.

Aquí no sólo partimos de una entidad diferente, ya que son esos estados que se constituyeron con el paso al estado liberal los que deciden integrarse en una realidad distinta, sui generis, a la que están dispuestos a ceder parte de su esencia, pero sin renunciar a dejar de ser Estados que conforman la realidad. Por otro lado, se suma una dificultad adicional que no se dio de igual forma en los procesos de formación de los estados liberales, que es la identidad propia de los individuos que pertenecen al Estado. Nos resulta sumamente importante tener en cuenta el papel de los ciudadanos en la Unión, no sólo por el hecho -que en sí mismo ya es lo suficientemente importante y desde

${ }^{7}$ Considerando el estadio actual de la Unión nos parece un poco pronto para el surgimiento de estos movimientos. No obstante, los consideramos una prueba de la debilidad de la Unión que no ha sabido crear una identidad común. Ciertamente este tipo de movimiento son casi naturales pero lama la atención que antes siquiera de haber finalizado el proceso ya surjan fuerzas centrífugas, máxime cuando la idea de la Unión es la unidad de Europa frente a los desastres que había conllevado la contienda mundial.

Puede leerse al respecto VEIGA COPO, A., «Mito o realidad: de actor local a global», en de Tomás Morales, D., Vaquero Lafuente, M. E. (Coords.), El día de Europa: la Europa de los 25, Universidad Pontificia Comillas, Madrid, en particular, pág. 36 y ss.

Cuestionado sobre el euroescepticismo, DAVARA, F. opinaba en un sentido al que nos referiremos en páginas siguientes. Así, consideraba que era un asunto complicado de lidiar desde las Instituciones, por tanto, «se debería trabajar en las universidades y escuelas para enseñar lo que significa realmente Europa. El ciudadano debería tener más información sobre lo que significa Europa y que esta idea europea, fundamentada en creencias, no fuera sólo patrimonio de los políticos, sino algo que fuera aceptado y entendido». BENEDICTO Solsona, M. A., Angoso García, R., Europa a debate. Veinte años después (1986-2006), Plaza y Valdés, Barcelona, 2006, pág. 93.

También sobre el euroescepticismo comenta NEGRI, si bien para luego admitir, que, siempre desde su punto de vista, Europa importa y sobre todo al proletariado, que «el euroescepticismo no es una enfermedad de los débiles, sino una toma de posición realista de quién ha sabido observar el desarrollo actual». NEGRI, A., Europa y el imperio: Reflexiones sobre un proceso constituyente, Akal, Madrid, 2005, pág. 80.

${ }^{8} \mathrm{Al}$ respecto, por todos, Rosamod, B., Theories of European Integration, MacMillan Press, Nueva York, 2000, pág. 21. 
nuestro punto de vista el nuclear- de que los ciudadanos son o han de ser el auténtico centro de la Unión, lo que no se cumple a pesar de lo dispuesto por los Tratado, si es que de verdad queremos conseguir una unión política; sino por la importancia que supone como factor aglutinador con independencia del entorno (Estado) al que pertenezca o residan. Así, la dificultad principal, desde nuestro punto de vista, es la falta de una identidad, de una asimilación o identificación e interiorización del proyecto europeo.

Igual que no podemos decir a un ciudadano que ha de sentirse parte de un Estado si él no se siente parte de él, lo que debiéramos haber aprendido de la radicalidad nacionalista instalada en varios Estados Europeos ${ }^{9}$ por lo que a nuestro ámbito de acción se refiere, menos aún podemos obligar por la vía de una Constitución a los ciudadanos de los Estados a sentirse europeos. Desde nuestro punto de vista el sentimiento de pertenencia a la Unión se logra con el paso del tiempo, creando identidades comunes, haciendo a los ciudadanos participes del proceso, lo que implica entre otros factores que comentaremos seguidamente, hacer al ciudadano partícipe, lo que es mucho más que solicitarle un voto cada seis años. Es imprescindible acercar la Unión a los ciudadanos. Mientras ello no ocurra podemos incluso haber conseguido la articulación constitucional, pero nos atrevemos a decir que nunca tendremos una Unión fuerte, y por tanto, la estabilidad de una Europa cohesionada.

Consideramos que hoy podemos ir más allá de la idea de la Unión como un espacio para la cohesión de los Estados miembros, como un espacio de armonía y entendimiento mutuo tras las contiendas del siglo $\mathrm{XX}$, y profundizar en un debate serio y sobre todo sosegado acerca de dónde nos dirigimos y cómo queremos hacerlo.

El principal problema que muchos de nosotros encontramos para ello, y por tanto para el avance de la unión, dejando por un momento de lado la actual situación económica, parece seguir siendo hacia dónde vamos. En el momento en que aceptamos la Europa a distintas velocidades ${ }^{10}$, que de hecho significa más una Europa a la carta, dimos quizás un primer paso, quizás incluso sin saberlo, a la situación actual. Rompimos el consenso sobre cómo y dónde ir, para dejar que cada uno fuese y llegase según le conviniese, y en ello seguimos.

Desde el punto de vista económico podemos decir que existen objetivos claros - a pesar de lo que podemos denominar ciertas disfuncionalidades que

${ }^{9}$ En este sentido se puede decir que los nacionalistas igual que no tienen el sentimiento de pertenencia a un estado sí parecen tenerlo la unión. El proceso es paradójico aunque puede ser explicable considerando que la Unión anula parte de la soberanía del Estado.

${ }^{10}$ A esta Europa a distintas velocidades se refiere De Cueto Nogueras, C., «La ampliación oriental de la Unión Europea: Un proceso inacabado de revisión institucional» en Flores Juberias, C. (Ed.), Estudios sobre la Europa Oriental, Universidad de Valencia, Valencia, 2002, pág. 397 y ss., y en general, la Quinta parte de estos estudios «Desafíos de la integración Europea», págs. 371 a 450. 
ha mostrado la crisis actual-, que han derivado no sólo a establecer la unión como una unidad, sino a darle un sólido papel como agente económico, pero también un agente protector de los estados miembros en la actual crisis económica, muchos de los cuales hubieran afrontado seguramente incluso peor situación que la ya de por sí calamitosa situación en que se encuentran, si no hubieran estado bajo el paraguas comunitario, como la de Grecia, Italia, Portugal, España o incluso Francia.

La claridad de fines en lo económico, buscando consolidar un agente fuerte y poderoso que pudiera competir en igualdad con otras economías potentes, no sólo los Estados Unidos sino las emergentes economías asiáticas, tiene su más clara manifestación en el Euro. El Euro se ha convertido en un símbolo de la unión económica deseada y de alguna manera conseguida, pero de alguna manera también se ha buscado con él, infructuosamente, que fuera un elemento que contribuyese a la cohesión ciudadana y al logro de su sentimiento europeo ${ }^{11}$.

Lo que la Unión Europea no acertó a prever es que el sentimiento de pertenencia no existía por igual en todos los Estados, y que tampoco se iba a asentar por haber creado un símbolo sobre el que construir la Unión Europea y hacerla avanzar. De esta manera, hoy el euro no es más, ni menos, que una moneda. Pero una moneda que ninguno quiere dejar caer $^{12}$, a pesar del coste que supone, y de hecho está suponiendo, político y económico ${ }^{13}$, no sólo porque ello supondría una seria vuelta atrás, de alguna manera quizás irreversible en el proceso de la unión económica de los Estados miembros - de hecho el único breakthrough de la Unión Europea- pero posiblemente, conduciría a

${ }^{11}$ Esta idea del Euro como elemento de unión y de cohesión, y el error en ello, fue bien expresada por SCHWARTZ en un artículo publicado en Actualidad Económica en el 2011 que puede consultarse en http://www.pedroschwartz.com/dynamicdata/flash/Esperanzas-de-futuro.pdf.

${ }^{12}$ En este sentido se puede decir que la crisis ha hecho cambiar la posición al respecto. Si bien en sus primeros momentos se aceptó la idea de que todos los países del eurogrupo actuarían con unidad y se ayudaría a los débiles y no se dejaría perecer la moneda, hoy parece más probable la idea, frente a la posibilidad de que sea la moneda la que muera, que sean los países que no pueden permanecer los que salgan del Euro. En este punto es preciso dejar constancia de que esto ha puesto de manifiesto una de las muchas circunstancias no previstas cuando se llevó a cabo la unión económica y que deben hacernos reflexionar antes de proceder a una unión política que, al igual que la económica pueda resultar irrevocable una vez que se produzca. En el caso de la unión económica lo no previsto fue qué hacer si un país decidía salir del Euro o, qué hacer si un país no podía cumplir los criterios de convergencia. La solución a lo segundo parece más fácil y es la que muchos sugieren se tomará con Grecia, a pesar del alto coste que eso va a suponer en particular para algunos Estados Miembros que a su vez se encuentran en dificultades, como Francia.

${ }^{13}$ Sobre las consecuencias políticas quizás el ejemplo más claro sea el declive que se está produciendo en los Länder que han celebrado elecciones en el último año, cuyos resultados revelan una progresiva debilidad de A. Merkel, frente a su posición en Europa, cada vez más sólida y más euroentusiasta. 
un declinar de la Unión Europea, si el símbolo en que se ha hecho descansar la frágil arquitectura política de la Unión cae.

Quizás en este punto si podemos intentar ver un paralelismo con el proceso de creación política. La tan ansiada, desde los padres fundadores, creación de los Estados Unidos de Europa, como lo denominó Churchill, no parecía poder quedar en la configuración de una moneda única. Moneda que ha servido de alguna manera como punto, artificioso si queremos, en base al que poder construir una identidad nacional. Pero si bien podemos considerar que la unión económica terminaría necesariamente conduciendo a la unión política, y de ahí que considerásemos acertado comenzar por la creación del mercado único, no podemos decir lo mismo de los intentos por forzar esta unión política desde la creación de un corpus constitucional que sirviese de marco común de organización de la Unión.

La principal resistencia que se encontraban estos intentos ha venido desde el seno de la propia Unión, como vimos ocurrió con Niza y sobre todo con Lisboa. Se ha demostrado, una vez más, que no puede crearse el sentimiento o el deseo de pertenecía. Cuando surgieron los Estados liberales se puso de manifiesto que uno de las fortalezas de los nuevos estados fue la creación, y en el caso de aquéllos, articulación en torno a unas características comunes, que jurídicamente decidieron ordenarla bajo un texto constitucional. El proceso se produjo de alguna manera de forma inductiva, desde dentro, en cambio el proceso constitucional europeo se ha intentado realizar desde fuera, encontrando principalmente resistencias en los propios Estados, algunos de los cuales, como Inglaterra, ni siquiera decidieron sumarse a la moneda única. Es por tanto necesario preguntarse, y debieran hacerlo las autoridades comunitarias, si es verdaderamente un deseo de los Estados avanzar ya hacia la unión política o sólo está ello en el seno de la Unión, que necesita legitimarse y fortalecerse como órgano de toma de decisiones pero también dotarse de un auténtico poder, más allá de la representación de Van Rompuy y Ashton, más institucional que de auténtico poder y con una, al menos, cierta carencia de legitimidad, si bien han sido aún escasas las voces al respecto que se oyen en el seno de la Unión.

\section{EL PAPEL DE LOS ESTADOS EN EL PROCESO CONSTITUCIO- NAL Y EL LOGRO DE LA UNIÓN POLÍTICA}

Los Estados están necesariamente llamados a jugar un importante papel en la creación de la unión política. Pero no negamos, como no puede ser de otra manera y así lo venimos mencionando, el fundamental papel que le corresponde a los individuos, ya que al igual que son quiénes dan sentido a los Estados necesariamente han de terminar dando sentido a la Unión, a una unión que ha de ser más la Europa de los ciudadanos y menos la Europa de los pueblos.

En este sentido, comenta SÁNCHEZ MECA que «para poder hablar de una Europa como espacio democrático de acción política, hay que determinar las condiciones capaces de hacer posible la convergencia de las voluntades y la participación efectiva de los ciudadanos en sus órganos e instituciones. Dicho 
en otras palabras, hay que ponerse de acuerdo, ante todo, sobre qué bases los europeos podrían formar un conjunto cohesionado de ciudadanos capaces de darse democráticamente leyes a sí mismos; qué conciencia europea tienen o sobre qué identidad común se podría legitimar esa composición de Europa como entidad política supranacional» ${ }^{14}$.

Si bien ese momento es el deseable hemos de ser conscientes de que como instancia intermedia entre la Unión y los ciudadanos, debido a cómo se ha configurado la Unión, a los Estados les ha sido asignado un papel nuclear en la construcción de esa aún utópica unión política.

Podemos identificar dos aspectos en los que sería deseable la implicación gubernamental en la coyuntura actual de crisis de la Unión. Por un lado, realizar una labor que podríamos denominar pedagógica para transmitir a los ciudadanos comunitarios qué implica, y qué importancia tiene, pertenecer a la unión y ser, por tanto, ciudadanos comunitarios. Evidentemente, ello no supone, como comentaremos seguidamente, que se tenga que imponer a los ciudadanos ningún tipo de opción, ésta ha de ser alcanzada por ellos mismos, de ahí que denominemos esta labor pedagógica y no instructora.

Por otro lado, aún cuando no defendemos la necesidad, al menos de momento, de que tenga que existir una constitución en el sentido ortodoxo, sí es precisa su implicación en un proceso que se puede denominar metaconstuticonal, implicándose en la definición no sólo de los principios que han de dar soporte a la unión, los recogidos en el artículo 6 del TUE, sino también de los límites, incluso geográficos, de la Unión.

Retomando el primero de los aspectos apuntados. Avanzar hacia una futura unión política requiere, inexorablemente, al menos desde nuestro punto de vista, implicar activamente a los individuos en el desarrollo comunitario. A esta idea ya nos hemos referido, pero no hemos de olvidar otra que no hemos mencionado y que consideramos igualmente importante, y es que, de nada sirve que los ciudadanos sean europeos si los Estados no son también europeos ${ }^{15}$.

${ }^{14}$ SÁNCHEZ MECA, D., «El sueño de una Europa de los pueblos: el dilema entre identidad y diversidad», págs. 71 y 72 Puede consultarse el texto en http://www.fundacionfaes.org/record file/filename/623/00084-02_-_el_sue_o_de_una_europa_de_los_pueblos.pdf

${ }^{\overline{15}}$ Con ello queremos decir que los Estados tienen que hacer suyo también ese sentimiento de pertenencia. Esta circunstancia se observa mejor en los países de la Europa oriental que se sienten profundamente europeos, en los de la Europa occidental Alemania es quizás de los países que más interiorizado tiene su sentimiento europeo, lo que no es extraño teniendo en cuenta el papel que le corresponde y su propia historia. Como muestra de la importancia de ser europeos antes que nacionales merece la pena citarse un discurso de A. Merkel en el parlamento alemán el pasado mes de septiembre mientras se debatían los presupuestos, en el que hacía una defensa encendida del Euro como unidad al tiempo que proponía modificar los tratados para hacer avanzar la Europa. Ante ello, mencionar, que Cameron, por ejemplo, respondía (en parte, podemos decir, antes la necesidad de reforzarse por las voces euroescépticas surgidas en su propio partido) diciendo que aprovecharía la reforma de los tratados para hacer avanzar sus intereses nacionales. 
La Unión Europea es vista hoy por una amplia mayoría de ciudadanos como una realidad extraña de nulos efectos sobre sus vidas, y en la cual poco pueden intervenir o participar. Resulta, a ojos del ciudadano un organismo internacional en el periódicamente participan en las elecciones al Parlamento, cuya composición es también desconocida para ellos, y en las que además se da la circunstancia de que en la mayor parte de los Estados, incluido España, son vistas más como un plebiscito nacional que como elecciones comunitarias ${ }^{16}$.

Desde nuestro punto de vista es absolutamente imprescindible conseguir la implicación de los individuos en la construcción de la Unión, lo que no ocurre con el sistema actual. Alcanzar un verdadero proyecto de integración europea requiere como condición sine qua non, tal y como comentábamos hace unas líneas, que los ciudadanos se sientan pertenecientes a Europa, no en un sentido geográfico, sino en un sentido similar a como se sienten ciudadanos de sus respectivos Estados. Esta circunstancia es la que llevará a que sean capaces de pensar y considerar la Unión Europea, pero ninguna de estas metas puede conseguirse con el modelo actual.

En este sentido coincidimos con JÁUREGUI cuando comenta que «no es posible avanzar en la integración Europea si los gobiernos nacionales y, sobre todo, si los pueblos europeos no llegan a la conciencia de esta necesidad imperiosa de ser algo más que el cinco por ciento de la población del mundo que representa Europa $\rangle^{17}$.

No obstante, avanzar en esta consideración requiere un paso más que da CRUZ Villalón y en el que no nos detenemos por escapar a nuestras reflexiones, pero que sin duda ha de ser objeto de estudio, y es la existencia o no de un pueblo europeo, una auténtica ciudadanía europea en nuestras palabras. Así, CruZ Villalón dice que «en cuanto sujeto de Constitución, Europa-el pueblo o los pueblos europeos. Plantea el problema elemental y básico de su misma existencia. Y ello tanto en un hipotético momento constituyente como en cuanto pueblo constituido. ¿Dispone Europa de un demos, es decir, de un pueblo formado directamente por ciudadanos, o por el contrario, sólo dispone de «ciudadanos colectivos» a modo de un «superleviatán» integrado por leviatanes menores? $»^{18}$. Desde nuestro punto de vista, como ya hemos dicho, es clara la respuesta negativa: carecemos de un conjunto de ciudadanos europeos como tales.

${ }^{16}$ Sobre la lectura en clave nacional: podemos remitirnos, entre otros muchos, a MAIZ, R. (Ed.), Construcción de Europa, democracia y globalización, Vol. 1., Universidad de Santiago de Compostela, Santiago de Compostela, 2001, o el estudio de ZUGASTI, R., LAFUENTE, P., sobre la cobertura de las elecciones de 2009, que puede consultarse en http://mhcj.es/2011/08/20/zugasti_lafuentel

${ }^{17}$ Jauregui, R., Prólogo a Tajadura Tejada, J., Luces y sombras del Tratado de Lisboa, Comares, Granada, 2010. pág. XVIII.

${ }^{18}$ Cruz Villalón, P., La Constitución inédita. Estudios ante la constitucionalización de Europa, Trotta, Madrid, 2004, pág. 37. 
Ciertamente el cambio es complicado, ya que supone, de alguna manera, cambiar una forma de pensar y relacionarse con unas instituciones. Por ello es complicado, por no decir prácticamente imposible, dar una única respuesta a cómo hacerlo. A la propia dificultad de responder a esta pregunta, que se adivina por su propio planteamiento, sumamos otra derivada del propio ámbito sobre el que la formulamos. Las realidades de cada Estado miembro son diferentes, también lo son sus ciudadanos ${ }^{19}$, a pesar de que existen características comunes a la mayor parte de ellos. Debido a estas realidades sociológicas distintas, e incluso a su forma de comprender la Unión, es difícil establecer una forma similar de hacerlo en todos los países.

Parte de esta dificultad y de esta distinta forma de ver la Unión deviene de la propia complejidad interna de aquélla. Así, es vista por la mayor parte de ciudadanos como un complejo y burocrático entramado de instituciones que, lejos de haberse simplificado por los recientes cambios en los Tratados se ha complicado aún más ${ }^{20}$.

No es fácil lograr de repente que los ciudadanos sean conscientes de la importancia de la Unión Europea, pero es importante acercarla a los ciudadanos, lo que implica que se sientan partícipes de lo que ocurre en Europa y de su participación en la toma de decisiones de importancia. A menudo se ha acusado a la Unión de un déficit democrático. No podemos sino coincidir con dichas críticas, ya que el papel reservado al ámbito de decisión de los ciudadanos es tan reducido que resulta aparentemente inexistente como venimos comentando.

Hemos trazado en varios momentos una leve analogía entre lo que supuso la creación de los estados liberales con lo que supone la Unión, como procesos en los que la segunda pudo haber imitado lo que verdaderamente hace que el primero aún perviva. Si consideramos en este punto la participación ciudadana, no podemos hablar de un auténtico estado democrático, en el que los ciudadanos participen, si ellos no toman parte en las decisiones. Al igual que ocurre en los estados nacionales, dónde ningún ciudadano ignora que lo que ocurre a nivel gubernamental y parlamentario les afecta, lo mismo debiera ocurrir con la Unión ${ }^{21}$, y no circunscribirse a los asuntos económicos, para los que nadie duda que existen determinadas decisiones que se toman a nivel

${ }^{19}$ Podemos decir que es un claro ejemplo de esto el nivel de participación e implicación en las elecciones europeas, lo que es sólo una manifestación, y quizás no la más importante, aunque sí visual, de la falta de interés en los asuntos comunitarios.

${ }^{20}$ Evidentemente a esta consideración escapan los expertos, que no son la mayoría. Por el contrario sí lo son aquéllos que no entienden su funcionamiento, sus funciones os u importancia.

${ }^{21}$ En este sentido, quizás podríamos destacar, lo que merecería un mayor análisis la visibilidad de la Unión, refiriéndonos con esto al papel que ocupa en los medios de comunicación por ejemplo, aceptando como tesis que, como decía SARTORI, G. en el Homo videns, lo que no sale en los medios no existe. Esta falta de visibilidad de la Unión no contribuye a que los ciudadanos sean conscientes de ella. 
comunitario y que entran en juego cuando suben o bajan los tipos de interés, $\mathrm{y}$, en los últimos meses, con la subida de la prima de riesgo, pero quizás sí ignoran que todo lo que ocurre en Europa nos afecta porque en la mayor parte de las ocasiones, y desde luego en más de las que sería deseable, legisla, limita e interviene en nuestros asuntos internos.

Conseguir una auténtica Europa de los ciudadanos que nos conduzca a la unión política no sólo supone una pedagogía interna a la que nos hemos referido, ha de venir fundamentalmente de parte de la Unión que ha de conseguir trasladar su centro de los Estados a los ciudadanos. En los modernos estados el territorio parece haber desplazado al ciudadano como centro, lo que nunca debió haber ocurrido, y eso parece mantenerse en el seno de la Unión, donde incluso se habla de intereses particulares de un determinado estado en lugar de hablarse de los intereses de los ciudadanos de dichos estados. El cambio tiene que venir evidentemente desde la propia Unión, de otra forma, se seguirá viendo más como un lugar para los Estados que para los ciudadanos.

Así, se da la curiosa circunstancia de que en la Unión Europea ocurre, $a b$ initio, lo que ha ocurrido con el nacionalismo en muchos estados europeos, que ha colocado al territorio como centro desplazando al ciudadano. En la Unión Europea ello ocurre desde el principio, y, salvando la configuración del Parlamento, en el resto de las Instituciones pesan más los Estados nacionales que los ciudadanos. Ello supone enfrentarnos a un proceso complicado que levanta suspicacias, algunas de las cuales son intrínsecas a la propia configuración de la Unión, como la cesión de soberanía.

En este sentido, si el centro parecen ser los Estados en lugar de los ciudadanos, y además carecemos de ningún tipo de representatividad directa de los ciudadanos, más allá de la europarlamentaria, nos encontramos en la situación de que ceder soberanía a la Unión resulta de alguna manera, como cederla a los Estados más fuertes en ella ${ }^{22}$. No obstante, ello no implica negar que los Estados tengan que seguir manteniendo un importante papel, máxime cuando tal y como está constituida hoy la Unión y el contenido de los Tratados, los Estados tienen el papel principal en la configuración europea, y actualmente, son una parte fundamental para sobrellevar no sólo la crisis económica, que les exige medidas de ámbito interno, sino en particular para solucionar la parálisis institucional en que se encuentra ahora la Unión y que deriva de lo ocurrido con el fallido intento de constitución tras lo ocurrido con el Tratado de Lisboa y la Sentencia del Tribunal Constitucional Alemán de 2009.

${ }^{22}$ Se puede citar como ejemplo la situación actual, en la que es evidente que en gran medida la política europea actual es marcada por Alemania, lo que supone, sin entrar en otras consideraciones que pudiéramos realizar, que existe una supeditación de los estados miembros a Alemania, que ha ocupado un papel preeminente basado fundamentalmente en su indiscutible hegemonía económica en la Unión. 


\section{4. ¿REALMENTE ES IMPRESCINDIBLE UNA CONSTITUCIÓN EU- ROPEA?}

En este punto procede considerar cómo avanzamos y si para ello es necesario o no contar con un texto constitucional. Como ya hemos indicado anteriormente partimos de que quizás no sea necesario contar con un texto constitucional en el sentido ortodoxo. Así, coincidimos con GARCía GESTOSO ya que, en sus palabras «un estudio del fenómeno comunitario, consciente de sus verdaderas limitaciones, debe comenzar por reconocer la insuficiencia del aparato categorial que, en principio, debe permitir explicarlo, sin renunciar, no obstante, por ello a emplearlo» ${ }^{23}$.

Esta circunstancia supone en primer lugar que es preciso definir, como ya hemos comentado, hacia dónde se dirige la Unión. De hecho, qué es la Unión Europea, no sólo en términos de valores y principios -que podemos encontrar claramente definidos en los Tratados y en la propia Declaración de Copenhague-, sino de estructura, lo que implica considerar aspectos territoriales.

Es transcendental tener en cuenta que sólo conociendo qué nos une como europeos, qué nos define, y a dónde queremos ir y por qué, podremos decidir sobre unas bases sólidas y duraderas no tanto nuestra propia pertenencia sino nuestro futuro en la Unión. Así, sólo tras una plena conciencia y consideración de todos los elementos podremos embarcarnos o no en el proyecto europeo con la libertad que proporciona el conocimiento sobre lo que decidimos, y, en el caso que decidiéramos hacerlo con reservas, servirá para conocer en base a qué es preciso repensar Europa. Lo que carece de sentido y no ayuda en el proceso de construcción europea es la redefinición constante de las reglas del juego y la excesiva flexibilización europea para dar cabida a los Estados que se suman a este proyecto.

Definir los principios y valores que nos guían es la tarea más fácil y a la vez la más difícil que hemos de afrontar en este proceso constitucional en que nos encontramos. Es fácil considerando no sólo que muchos de ellos ya están de hecho en los Tratados y forman parte del acervo comunitario, sino que podemos decir que todos los países miembros de la Unión tienen raíces políticas y constitucionales similares. La mayoría de los países que se unieron con posterioridad, incluso en épocas más recientes, a aquéllos que iniciaron sus procesos constitucionales con posterioridad a la II Guerra Mundial, han adoptado constituciones similares a aquéllas que existían en otros estados, basadas, fundamentalmente, en los principios del Estado de Derecho.

Pero a la vez, no puede ser ignorado que existen distintas circunstancias nacionales que no pueden dejar de ser tenidas en cuenta en este proceso constitucional. Quizás pasado un tiempo puedan ser mitigadas, pueden incluso

${ }^{23}$ García Gestoso, N., Soberanía y Unión Europea. Algunas cuestiones críticas desde la teoría de la Constitución. Marcial Pons, Madrid, 2004, pág. 20. 
desaparecer, pero no pueden ignorarse por la vía de la asimilación. Así, tal y como señala CRUZ VILLALÓN «los ordenamientos nacionales no sólo están llamados a converger sino también a divergir; en realidad, deberían hacer ambas cosas. Las constituciones contendrían así tanto un programa armonizador como un programa singularizador. Las constituciones contendrían al menos potencialmente un propio programa de asimetría, lo que nos llevaría a plantear la idea de la asimetría como bien constitucional. La categoría ideal de Constitución operará tanto fundando unidad como fundando singularidad $»^{24}$.

Es importante que este proceso sea liderado por los gobiernos nacionales, aprendiendo de sus propios éxitos y fracasos nacionales, lo que supone evitar repetir los grandes fracasos que se han cometido en los estados nacionales en la Unión. Esto implica además evitar uno de los mayores errores, desde nuestro punto de vista, de la actual Unión Europea, también de los Estados, y que puede conducir a su colapso, como ha conducido al de algunos estados y a otros los está conduciendo. El excesivo control e intervencionismo, particularmente en aspectos económicos, y el paternalismo estatal, como el que resulta de los estados sociales que aún no han acometido las reformas necesarias para modernizarlos, como el español, sólo resulta en una superestructura internacional que negaría la libertad del individuo.

Una vez que hayamos definido no sólo los principios sino los valores podemos avanzar hacia el siguiente paso, y preguntarnos entonces si hemos de regular y positivizar, y cómo, este marco en forma de Constitución.

Aunque somos muy conscientes de la importancia del movimiento constitucional, no consideramos esencial para la consecución de la unión política la promulgación de un texto constitucional. Ello no implica que ignoremos que para lograr la unión política hemos de superar categorías establecidas y arraigadas en las naciones y pensar y definir otras categorías supraestatales que definan mucho mejor el proceso que tratamos de acometer. Eso no significa abstraerse del todo de las categorías que ya conocemos, ya que, como no podía ser de otra manera, no dejan de ser el sustrato del proceso de configuración europea, pero, es necesario superar categorías que pueden resultar insuficientes y asumir las especificidades propias de este proceso e incluso definir sus propias categorías.

Quizás sea irrelevante decir, o incluso considerar, que el proceso de globalización en que nos encontramos necesariamente nos va a conducir a nuevas formas de relacionarnos en un plano internacional, de hecho ya lo estamos viendo, lo que afecta no sólo desde un punto de vista económico, circunstancia que ya hoy damos como natural, sino que afecta también a otros aspectos.

Si pensamos desde una perspectiva política, que es lo que ha de llevarnos a avanzar en nuestras consideraciones, es que hoy afrontamos no sólo nuevas

${ }^{24}$ Cruz Villalón, P., La Constitución inédita. Estudios ante la constitucionalización de Europa, Trotta, Madrid, 2004, pág. 47. 
realidades internacionales sino nuevas realidades internacionales en las que confluyen nuevos agentes internacionales, de todo tipo, y esto es lo que ha de llevarnos a reconsiderar qué sentido tienen los estados nacionales como entidades autónomas e independientes en un escenario político global.

Desde nuestro punto de vista aquí es dónde se ha de insertar el cambio en la Unión, lo que tendrá que suponer una transformación radical de sus estructuras, lo que conducirá a su transformación, suponemos que fortaleciendo su postura, caso contrario podría conducir a su estancamiento.

Evidentemente este cambio no tiene por qué articularse irremediablemente en una Constitución. Consideramos que lo sustancial si queremos avanzar hacia la unión política es crear la estructura para que efectivamente pueda producirse ese tránsito y avanzar verdaderamente a una unión de estados en el viejo continente. El hecho de dotar a esta nueva estructura de un texto jurídico que la articule lo consideramos únicamente una cuestión de forma no de fondo, por cuanto, de hecho, la Unión ya se encuentra desde hace años inserta en un sui generis proceso constitucional.

En este sentido, es preciso relativizar el concepto de Constitución, como nos enseñaba ScHMITT, puesto que el hecho de contar con un texto constitucional del modo que lo concebimos cuando pensamos en él no es constitutivo del hecho de contar con un Estado constitucional ${ }^{25}$. Si observamos el proceso que ha seguido la Unión y como se ha construido normativamente, desde las decisiones jurisprudenciales pasando por las Conferencias Intergubernamentales hasta el actual proceso de las Convenciones, vemos un continuum que ha ido dando lugar al proceso actual. Es cierto que consideramos que esta última fase se ha intentado hacer por la vía de la imposición, lo que se ha encontrado con el rechazo frontal de los Estados, pero ello no ha de suponer que consideremos que el proceso está agotado y llamado a perecer.

Lo que sí podemos avanzar, antes de concluir, es que si bien el propio texto constitucional lo consideramos irrelevante, y quizás incluso inapropiado en estos momentos, no cabe duda de que nos encontramos ante un proceso que terminará derivando en la articulación normativa del mismo.

\section{CONCLUSIONES}

La realidad de la crisis económica ha puesto de manifiesto ciertas debilidades en el seno de la Unión que hacen que se tenga que hacer frente, en un corto espacio de tiempo a una crisis de legitimidad si verdaderamente quiere producirse un avance y no caer víctima de la actual situación.

En este contexto nosotros hemos considerado que es preciso abrir los horizontes y no considerar que la crisis actual es sólo una crisis económica, sino una crisis global, a todos los niveles y en todas las estructuras, que supondrá

\footnotetext{
${ }^{25}$ Schmit, C., Teoría de la Constitución, Alianza Editorial, Madrid, 2011, pág. 45 y ss.
} 
un replanteamiento de muchas realidades tal y como las conocemos actualmente, y desde nuestro punto de vista, la Unión Europea no es ajena.

Es aquí donde vemos la oportunidad para la Unión Europea. Estimamos que en estos momentos la Unión se encuentra en un proceso de estancamiento institucional que trae causa en el fallido intento de la Constitución para Europa, por simbolizar en ella el fracaso constituyente europeo, que se ha visto además aún más lastrada por una crisis en su seno que, si bien la económica es su más cruel manifestación, afecta a todos sus ámbitos. En este punto es dónde se encuentra a la vez la amenaza y la gran oportunidad para la Unión.

Consideramos que el proceso actual es sólo una fase más en el proceso de configuración comunitaria que ha sabido crecer mejor a través de sus crisis que de sus periodos de expansión, y esta crisis no tiene por qué ser menos. El replanteamiento del papel de la Unión, su inserción como un actor más y de gran relevancia en el contexto internacional, la relación con los ciudadanos y con otros Estados, son procesos que ya estamos viendo y que conducen a la transformación de esta organización.

No estamos concibiendo por tanto el hecho de que la Unión no se vea obligada a cambiar, sino todo lo contrario, ya que, de no producirse este cambio perecería víctima de su propio anquilosamiento. Así, igual que la caída del absolutismo dio lugar a un replanteamiento de las formas de ejercicio del poder, el nuevo orden internacional y la variedad y multiplicidad de actores en el mundo actual ha cambiado radicalmente la forma en que los estados se relacionan entre ellos y con los individuos y organizaciones de todo tipo.

No consideramos que sea aventurado decir en este punto que nos encontramos en un periodo preconstituyente y que consideramos que, con anterioridad a entrar plenamente en el periodo constituyente se han de explicitar ciertas bases e incluso poner límites a la Unión, caso contrario se corre el riesgo de decaer víctima de un exceso de ambición.

La Unión Europea no puede ser una organización internacional más y por tanto, como no es una institución igual que las que conocemos es indispensable que se determine como primer paso los límites territoriales y materiales de la Unión para, desde ahí, empezar a conjugar los papeles que se le piden a los distintos actores para terminar consiguiendo la total implicación ciudadana, sin la cual la futura unión política se nos antoja imposible.

De esta forma, estamos convencidos de que este periodo de crisis servirá para alumbrar la Unión Europea del futuro y no hemos de desaprovecharlo, pero a la vez, hemos de tener en cuenta la experiencia que hemos adquirido ya para evitar procesos fallidos y debilitar con ello a la Unión.

En este sentido además, y teniendo en cuenta hacia donde ha derivado la Unión, procede decir que de nuestra historia hemos aprendido que es necesario, indispensable, poner límites al ejercicio del poder y la injerencia estatal en la libertad de los individuos. Esta señal no se debe dejar de tener presente en el proceso de construcción europea y los estados nacionales no han de perder la oportunidad de liderar este cambio. 